\title{
DETERMINATION OF THE MAXIMUM AIR TEMPERATURE TOLERATED BY \\ RED PINE, JACK PINE, WHITE SPRUCE AND BLACK SPRUCE SEEDS AT LOW RELATIVE HUMIDITIES ${ }^{1}$ \\ BY ALAN J. CARMICHAEL
}

\section{INTRODUCTION}

The extraction of seeds from cones by means of infra-red radiation and the warm air convection kiln at the Ontario Tree Seed Plant, Angus, have shown an occasional reduction in germinative energy, the cause of which was not known.

In order to test certain possible causes, a test cabinet was constructed in which the atmospheric conditions of temperature and humidity could be controlled within the range of $120^{\circ}-180^{\circ} \mathrm{F}$, and $10 \%-30 \%$ relative humidity. The tolerance of seeds of red pine, jack pine, black spruce and white spruce, to various temperature-humidity combinations, was determined by exposing seeds to these conditions for periods of 10,30,50 and 70 hours. The seeds used had been subjected previously to a heat treatment during their extraction from the cones and had a moisture content of $2 \%-4 \%$. The criterion used to measure tolerance was the 10-day germinative energy figure as obtained by the Jacobsen method of germination testing.

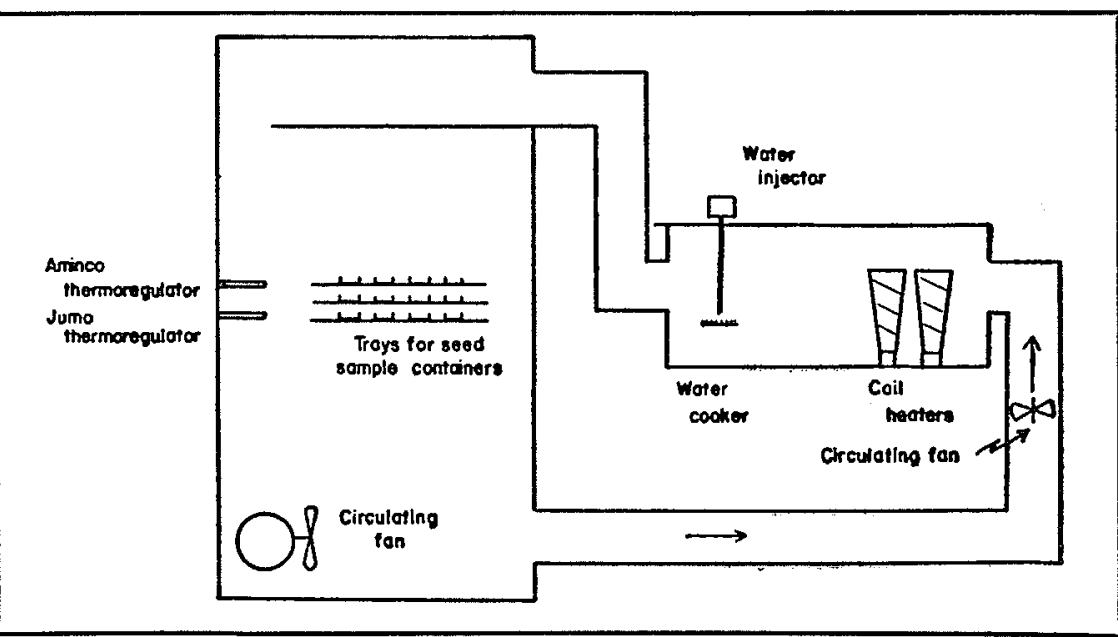

FIGURE 1

Diagram of test cabinet.

${ }^{1}$ Revision of thesis submitted in October 1956 for the degree of M.Sc.F. at the University of Toronto. Submitted for publication to The Forestry Chronicle, March, 1958. 


\section{Test Cabinet}

The basic cabinet was an $8 \mathrm{cu}$. ft. refrigerator with a treating chamber separated from it and connected by means of ducts. (Fig. 1.) The heating and moistening of air took place in this chamber and the treated air was forced into the test cabinet by means of a circulating fan.

Air temperature was measured and controlled by means of a bimetallic thermoregulator which operated two 660 watt coil heaters. A control of $\pm 1^{\circ} \mathrm{F}$ was obtained at the seed testing location in the centre of the cabinet.

Air moisture was measured and controlled by means of an adjustable contact mercury thermometer used as a wet bulb. The wet bulb thermoregulator activated a unit which allowed water to drop to a cooker. The cooker consisted of two plates, between which an electric current was carried by the drops of water. Heat, generated by the resistance of the water to the flow of

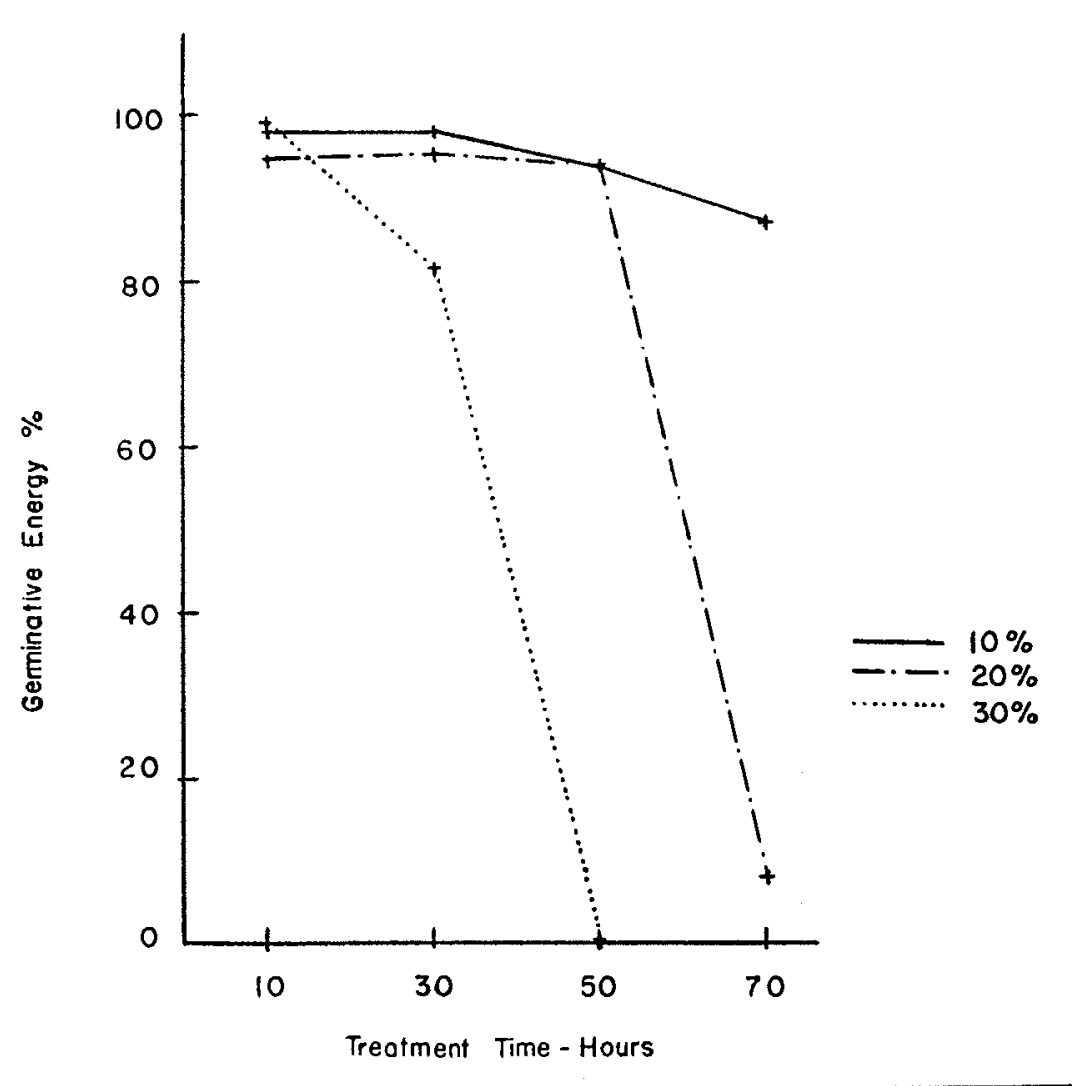

FIGURE 2

Time-humidity interaction for red pine at $180^{\circ} \mathrm{F}$. 
electrical current, boiled the water and produced steam. This system allowed for a control of $\pm 2 \%$ in relative humidity within the range of $10 \%-30 \%$.

\section{RESUlts AND CONCLUSIONS}

Inspection of the germination data showed that the $180^{\circ} \mathrm{F}$. temperature resulted, in every instance, in an extreme reduction in the number of seeds that germinated, compared with the $120^{\circ} \mathrm{F}$. and $150^{\circ} \mathrm{F}$. temperatures. For this reason it was judged appropriate to analyse separately the data for $180^{\circ} \mathrm{F}$. and for the two lower temperatures. Standard analysis of variance calculations were used to separate the various sources of variation in the data.

The tests have indicated that high temperatures are much more damaging when combined with high humidities and applied over a long period. (Fig. 2, 3,4 , and 5.)

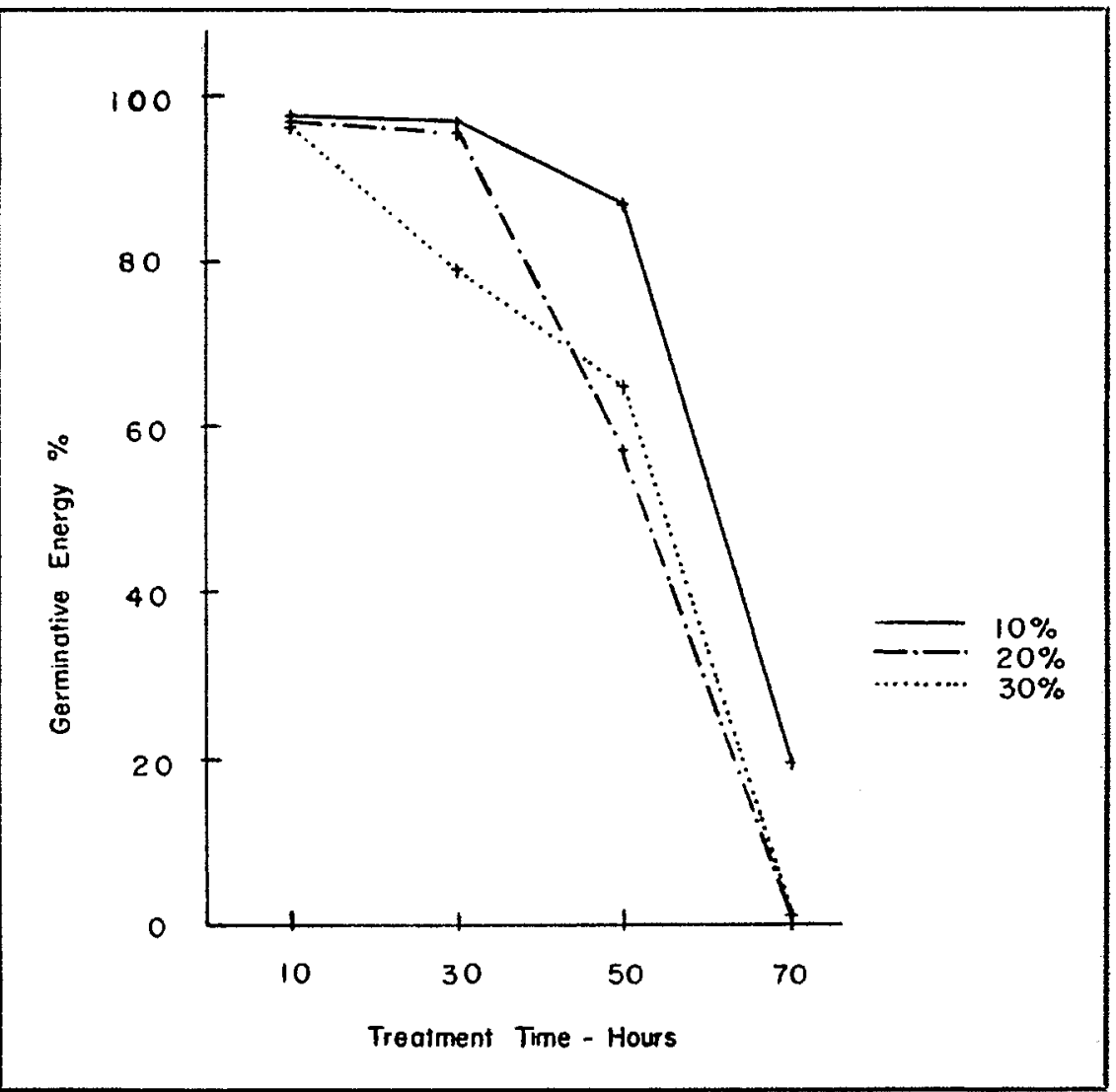

FIGURE 3

Time-humidity interaction for jack pine at $180^{\circ} \mathrm{F}$. 
For red pine, jack pine and black spruce $180^{\circ} \mathrm{F}$. was scarcely damaging while the relative humidity of the air was kept low. White spruce was an exception, but it remained almost unchanged at $150^{\circ} \mathrm{F}$. under similar circumstances. The results suggest that a short period of exposure at $135^{\circ} \mathrm{F}$. and $20 \%$ relative humidity would be safe. For each species, when the temperature became critical, at increasing humidities, damage became evident within progressively shorter intervals.

Red pine and black spruce showed a similar behavior, particularly at the $180^{\circ} \mathrm{F}$. temperature. They differed from jack pine in that they were more tolerant of long periods of exposure to the temperature-humidity combinations. White spruce differed from the other species in that the $180^{\circ} \mathrm{F}$. tempera-

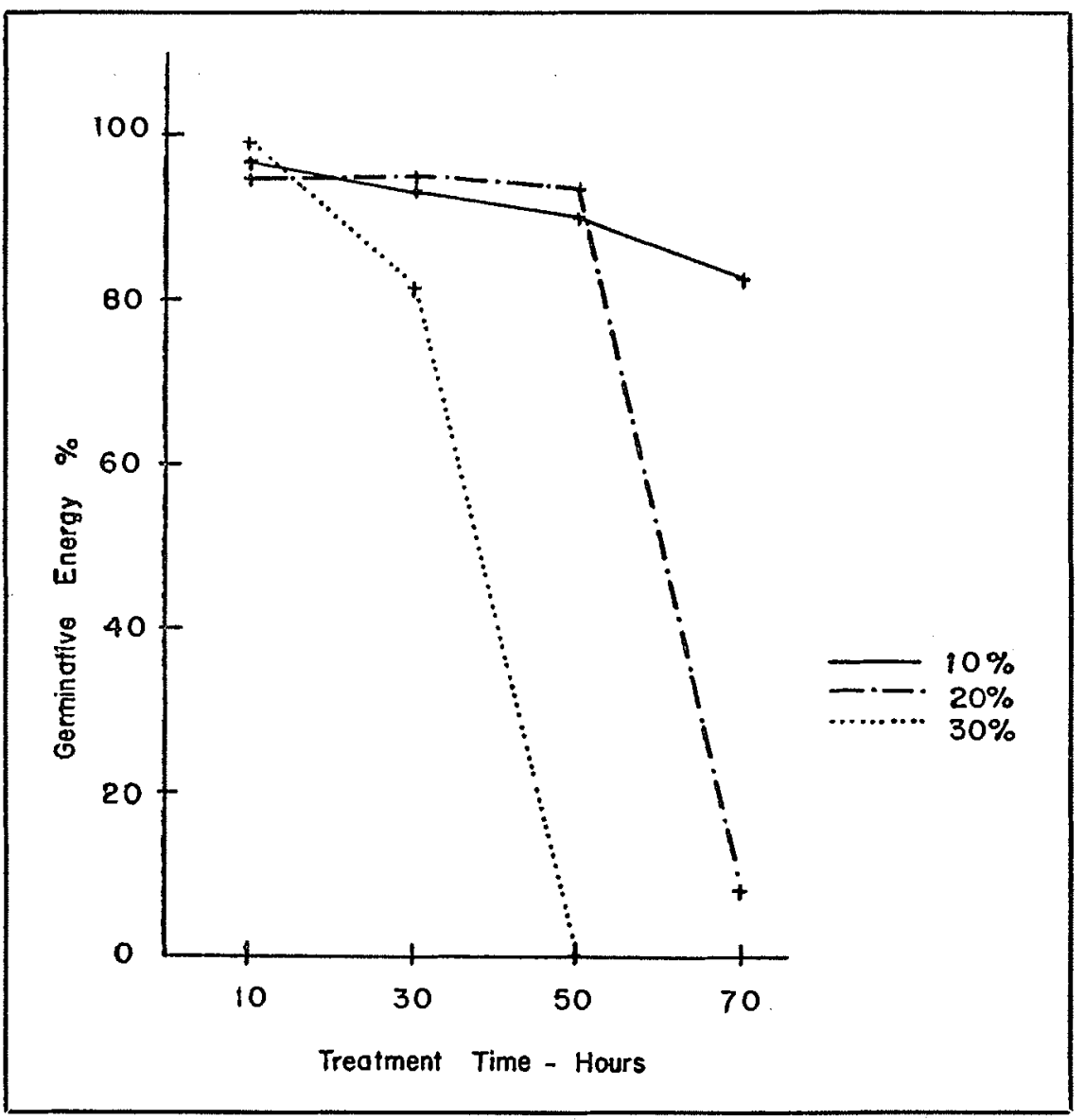

FIGURE 4

Time-humidity interaction for black spruce at $180^{\circ} \mathrm{F}$. 
ture was lethal under all circumstances. The highest safe temperature for this species was suggested to be $135^{\circ} \mathrm{F}$.

The safe limits of exposure in hours are shown in Table 1.

\section{TABLE 1}

SAFE Limits of Exposure (HOURS)

\begin{tabular}{|c|c|c|c|c|c|c|c|c|c|}
\hline Temperature & \multicolumn{3}{|c|}{$120^{\circ} \mathrm{F}$} & \multicolumn{3}{|c|}{$150^{\circ} \mathrm{F}$} & \multicolumn{3}{|c|}{$180^{\circ} \mathrm{F}$} \\
\hline Relative Humidity & $10 \%$ & $20 \%$ & $30 \%$ & $10 \%$ & $20 \%$ & $30 \%$ & $10 \%$ & $20 \%$ & $30 \%$ \\
\hline Red Pine & $70+$ & $70+$ & $70+$ & $70+$ & $70+$ & $70+$ & 30 & 30 & 10 \\
\hline Jack Pine & $70+$ & $70+$ & $70+$ & $70+$ & $70+$ & 50 & 30 & 30 & 10 \\
\hline Black Spruce & $70+$ & 50 & 50 & 50 & 50 & 50 & 30 & 30 & 10 \\
\hline White Spruce & $50-70$ & $50-70$ & $50-70$ & \multicolumn{3}{|c|}{$\begin{array}{l}\text { Conditions } \\
\text { too severe }\end{array}$} & \multicolumn{3}{|c|}{$\begin{array}{l}\text { Conditions } \\
\text { too severe }\end{array}$} \\
\hline
\end{tabular}

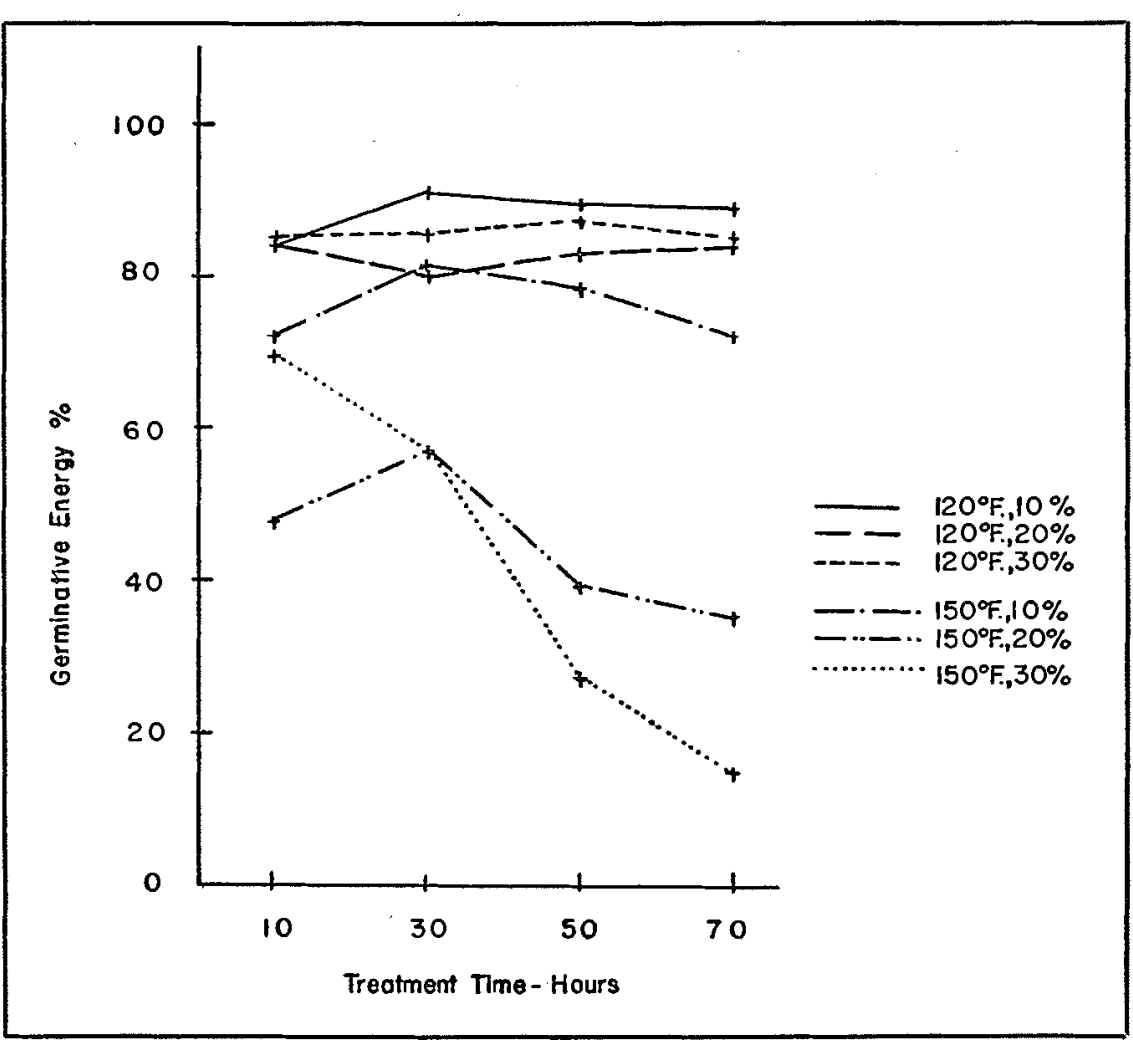

FIGURE 5

Time-temperature-humidity interaction for white spruce at $120^{\circ} \mathrm{F}$. and $150^{\circ} \mathrm{F}$. 


\section{ACKNOWLEDGMENTS}

Grateful acknowledgment is made to the following for the part which they played, in developing the test cabinet used in this study, in the analysis of experimental results and in furthering the tests in many ways: $R$. S. Carman and E. A. Lewis, former Superintendents, Ontario Tree Seed Plant; Dr. E. J. Zavitz and G. H. Bayly, former Chiefs, Division of Reforestation, Ontario Department of Lands \& Forests; Dr. J. W. B. Sisam, Dean, Faculty of Forestry, University of Toronto; Dr. J. H. Downer, dental surgeon in Toronto; Dr. D. B. Delury of the Ontario Research Foundation; and Mr. L. M. Morrison, former statistician with the Ontario Department of Lands \& Forests.

\section{REFERENCES}

CARMICHAEL, A. J. 1949. Comparison of infra-red lamps and convection kiln in tree seed extraction. Ontario Department of Lands \& Forests, Res. Rep. 20.

HODGMAN, C. D. 1951. Handbook of chemistry and physics. 33rd. ed. Chemical Rubber Publishing Co.

PEARCE, S. C. 1953. Field experimentation with fruit trees and other perennial plants. Comm. Agric. Bur. Tech. Comm. 23.

RIETZ, R. C. 1941. Kiln design and development of schedules for extracting seeds from cones. U.S.D.A. Tech. Bull. 773.

Anonymous, 1953. Heating and ventilating air conditioning guide. 31 st ed. Am. Soc. Heating and Ventilating Engineers. 